\title{
Use and Beauty_—Research on Soetsu Yanagi's Theory of Folk Art
}

\author{
Peng Fangyan \\ Arts College of Sichuan University, Chengdu, Sichuan, 610044 \\ Jincheng College of Sichuan University, Chengdu, Sichuan, 611731
}

Keywords: Soetsu Yanagi, the Theory of Folk Art

\begin{abstract}
There is a clear method for the design and art practice and the development of the theory in Japan. Among them, the folk art of Soetsu Yanagi's theory manifests the value orientation of national art design theory in Japan, and it is also one of the aesthetic characteristics of the Japanese nation, from folk artisans in real life, who are amiable, careful and simple. The art of Soetsu Yanagi's theory, based on the technology of public values, reshapes social process, operational ability, practical beauty, natural endowments, and human origin. The introduction of the theory of civil art and the continuation of the civil art lay a solid foundation for the construction of a good and inclusive design culture of Japan.
\end{abstract}

\section{Introduction}

Japanese art design practice and theory development there is a clear road, at the beginning of 1860s, Japan was the western capitalist industrial civilization and the impact of modern reform movement has the nature of capitalism -- by the reform movement, a move that has gradually entered the industrial age of japan. Less than forty years after World War II, Japan has become a powerful economy, and Japan's design is also known worldwide in many fields [1]. In 1950s, the American designer Raymond Rowe in Japan for three weeks, in the postwar Japanese design seminar, the meeting he put forward "Japan itself has a rich cultural heritage, there is no need to copy other countries' view. Raymond Rowe won the praise behind, we have to see the Japanese design system of mature base -- a good foundation since Meiji decades laid at the same time, this period is also the Japanese design system of early exploration, and national design concept formation stage [2].

During this period, Soetsu Yanagi (1889-1961), the father of the Japanese folk art, advocated the concept of folk art, which is an important link in the exploration of Japanese design. In 1926, Liu Shi and others launched the Japanese folk art movement, founded the Japanese Folk Art Association and the Japanese folk art hall, preserving the Japanese national culture and spreading the rustic folk art beauty to the public [3]. The folk art heritage of the aesthetic characteristics of traditional Japanese art ethnic distinctive, amiable, humane, small scale, meticulous and simple. Folk art is the abbreviation of "people's craft", and the field of folk art is the most widely used. Folk art must be meet all the needs of the people, practical, can be created, and a large number of cheap, made from the builders. In Mr. Soetsu Yanagi's folk art theory, we discussed the problems of hand making and machinery, the relationship between the beauty of use and the beauty of society, the relationship between technology and art. On the basis of the times, the views of aesthetic and practical and folk art saving the world are expounded [4-5]. Soetsu Yanagi's view of folk art has influenced the development of design in Japan and Asia, which has far-reaching influence on design practice or design theory research.

\section{Hand and Machine}

In the wisdom of the west, Russell wrote: "from the standpoint of humanitarianism, the early stage of industrialism is a period of creepy." This situation is generally in the early stage of social transformation for the popularization of industrialization. A war between Japan and the Second World War, capitalism in the early stages of economic restructuring, the transition from the tool age 
to the industrial age, Japanese society at that time of mechanized production of extreme fanaticism, or even the birth of "mechanical" worship such as Liu mentioned, that local handicrafts and crafts production is a product of the times backward [6]. Under the stimulation of the capitalist system, the folk arts were forced into the competitive market, so they had to use stimulant measures to survive in the market. The lack of color and shape in the sense of beauty is a direct reflection. At that time, the decline in the quantity and quality of the handicraft products in Japan, the handicraft products were no one, and a large number of hand craftsmen turned to change. Some Japanese local craftsmanship is also facing the danger of extinction; at the same time, the primary stage of Western mechanized production too blindly, Japan made out of industrial products is very rough product abuse made, but can not use fancy appearance [7]. In the face of such a situation, Soetsu Yanagi worried that, for profit first purpose capitalism kills folk art and beauty, and hand for creativity. In the folk art theory of Liu's, the attitude of the opponent's work and the machinery is fully expounded, which can be summed up to the following three points:

\subsection{Hand work is not out of date}

Soetsu Yanagi thought "it is no benefit to ignore the machinery of the auxiliary hand, but it is more ignorant to eulogize the machinery of the hand." The past of the age of tools is not equal to the loss of value by hand. The advent of the age of science has made the age of religion a past. However, no matter how scientific the science is that will not change the meaning of faith. The more it is in the age of science, the more the belief is required. The value of hand will not change. In the future, the requirements for the handwork will be repeated as a result of a different degree of awareness." It is true that tradition itself is not completely opposed to modernity, and it can be fully understood and re-understood through the process of modernization. As the tea in the hand by Soetsu Yanagi, folk art exhibition to face heavy.

\subsection{Machinery cannot replace hand work}

The first half of Soetsu Yanagi at the end of the nineteenth Century to twentieth Century is the beginning of the industrial society, Japanese arts and crafts crisis period. Machinery and industry often bring the new world life style to the public. At the same time, it is often very bad. Therefore, he thinks that the hand can be created, the machine is mostly imitation, and produces beautiful products within a certain limit. In the view of the Liu's view, the nature of the machinery itself is the creation of stillness and the prevention of beauty. Machinery is only a single, homogeneous repetition and imitation, only repetition, no freedom. He thought that without creation, it would not be possible to achieve beauty. There was not one utensil in mechanical products that could meet and surpass the beauty of handcraft. He seems to be in some sense with the tools and tools, but also a kind of machine, but from the beauty of the result, the handwork is always better than the machine. Because human hands are far more complex and free machinery than machinery, in any case the complex machine is much simpler than the hand. Soetsu Yanagi did not replace manual work for machinery [8]. From the perspective of appearance, there was indeed the limitation of the times. He was worried that machinery instead of human subjective creation, caught in a mechanical duplication and became a machine accessory. But judging from the judgement of value, he is very sure of the value of "hand", that is, the lofty nature created by human labor, and the ability of human labor to create is endowed by nature. Actually, everything is natural wisdom, and further rises to the sublime of natural creation. Machinery can not replace hand work, that is, the ability of machinery can not replace natural creation.

\subsection{Negation of "mechanism"}

Liu believes that machinery and capitalism are closely linked and pursue "interests" based on the nature of the capitalist society. Benefit from the constant consumption, continuous stimulation, replacement, purchase, discarded, can be said to be a new infinite loop, which is practical, and folk art in the view of simplicity, cherish and long for it, keep the values contrary. Especially at the beginning of twentieth Century Japan's popular "all kinds of evil mechanical materialism" brings, reflects the people in the industrial society at the beginning of childish ignorance. Liu believes that 
machinery is not good or bad, but overemphasizes machinery and is fascinated with "mechanism". It is useless to forget the creation of both hands [9]. He advocated the relationship between manual operation and machinery, that is, the relationship between man and machinery. Machinery is also a tool, and man is the master of tools. If people are "tools", they are made by nature. The first half of the last century, Soetsu Yanagi had to look to foresee the technology and people made mechanical and today's natural dialectics and the complex relationship between. At the same time, Soetsu Yanagi put forward the mechanical follow-up works based on the age. There are some limitations in hand finishing the following viewpoints. We can also tolerate these limitations with time and the particularity of the times to interpret them.

\section{Beauty of Use and the Beauty of Society}

With John Raskin and William Morris as the representative of the arts and crafts movement; Le Corbusie proposed "machine aesthetics" theory; Ulm system form follows function "3F" principle; Ludwig Mies van der Rohe proposed that "less is more"; Robert Venturi "less is boring" hundred years of thinkers to have on the different starting, tirelessly to discuss the relationship between function and form [10].

"Using" and "beauty" are the fundamental values of Liu Chung Yue's folk art theory. Soetsu Yanagi's reference to "beauty and use" is not only the judgement of function and form, but also elaborates and sublimes the two by deepening Aesthetics -- function and sensibility, and sensibility.

\subsection{The root of beauty}

The Japanese dictionary, "people" at the beginning of the word there are many words, culture and art related such as folklore, dialect, folk, proverbs, folk art, folk people tan, and so on, the definition of. Among them, "folk art" and "people's tools" belong to the research category of material culture. "Civilian implements" refers to "people's tools that are made by some technology on the basis of daily life needs".

The word "folk art" was put forward by Soetsu Yanagi in 1926. It refers to the practical living objects of folk handicraft, and the key words are folk, hand and practicality in the interpretation. In Liu's view, it is consistent with beauty and love. The beauty of the people's art is practical, healthy and close. The fundamental attribute of the utensils is for the use of people, and the use is not equal to the consumption. It is the real beauty of the utensils that the utensils are used to display their fundamental features. With the frequent use and increasing beauty, the love of heart giving is also increasing. If it is not used, utensils will lose their meaning and beauty will be gone, so it is the expression of beauty, and utensils are also the manifestation of real things. The function of "use" is understood as the function of things. This function is rooted in the daily life of the people, and "use" as the needs of the heart as the materialization of spiritual need. In the folk art theory, that is "beauty", "beauty is used". It is a healthy, stable and simple form with beautiful, harmless and healthy forms with the beauty of the utensils. It is the beauty of health. "Use" reflects the close relationship between beauty and the real world, and adds beauty to everyday life. This beauty is not sublime, not ordinary, but the most ordinary and ordinary beauty of everyday life. In the beauty of the craft, Soetsu Yanagi wrote, "the world that is lost is not the world of the craft." The process should help us to serve us and play a role. The service should be provided for everyone in the daily life. For practical service, it is the root of the process. Beauty is the beauty of practical process, all are produced in the service of the heart". The beauty of folk art can also be summed up in two words: "plain and astringent". It is also the materialization and culture of Japanese traditional national lifestyle.

\subsection{The beauty of nameless}

Soetsu Yanagi has been concerned about the western art movement since his early years. He once pointed out the relationship between artistic representation and personality traits based on the western modern individualism standpoint. Then, in studying Baroque and Gothic art, he realized that the rich historical materials in Oriental civilization should have Oriental consciousness different 
from western material civilization. From the beginning of folk art, folk art of Soetsu Yanagi around the world, the eastern United States began to elaborate. The western and Oriental beauty is relative share and multiple, people, group. 1926 is the beauty of "Miscellaneous (formerly known as: start beauty)" a "experience the beauty of the world", "everyone knows but not seeing the world" "the authors do not want to name, the world is full of unknown writer......" The beauty of folk art is unknown, is the daily necessities of folk artifacts made by many nameless builders, lack of cultural workers have no persistent personality, do not pay attention to their own name, often not engraved name is nameless maker; beauty and "in Ming" (with the name of the author Crafts) no matter the "relative" Ming (name of the author not carved crafts) the value of attention, pay attention to art subversion "genius" is better than "craftsman" individualism values.

From another point of view, behind the beauty of nameless, Soetsu Yanagi said the nation, the people's daily life tradition and the potential natural creation force of the people. John Raskin, a pioneer of Western arts and crafts movement, William Morris's theory and practice, based on the value of artistic beauty, wants to make ordinary life sublime. The beauty of fine arts is ideal to change society, on the ground things to the sky, and the aesthetic education is still the return of Ruskin art light of ideal, Maurice's ideal eventually become a fine art. The difference is, Soetsu Yanagi "beauty is simple, is people's labor, is the most natural life reality, is honest nature, can obtain cheap, plain idle light. He certainly folk craftsmen's creation, certain natural folk life and has been known as the "start" "miscellaneous" folk household appliances, but do not think that they must be applied to art pottery, that comes from the folk or country or natural life and fresh tomorrow is numerous living beings "unintentional nameless" folk art of the road.

\subsection{The belief in beauty}

Mark Diani (Marco Diani), a contemporary design frontier scholar, once said: in the past industrial society (or modern society), when people had relations with machines, they always dominated "instrumental rationality" or "computational rationality". In order to overcome the one sidedness, always as "instrumental rationality" of the typical design field, uncharacteristically, more and more the pursuit of a "no purpose, unpredictable and can not be measured accurately, the lyric lyrical value" Diani said without purpose and unpredictable value that is emotional, emotional is one of the most authentic cognitive ability.

"The heart is perplexed by the pure land, and is subject to the covenant of the present world... The holy lotus flower in the earth is the flower of the pure land, and the flowers which are given to the earth and blooming on the earth are now called the craft." The folk arts proposed by Soetsu Yanagi are impregnated with the breath of nation and faith. The beauty of the folk art is also the beauty of the sensibility. It is the religion of the East and the religions of the United States.

Soetsu Yanagi's folk art thought has distinct democratic enlightenment. He thinks all faults are derived from the disorder of social system. As long as the society is in rank and the gap between the rich and the poor, there will be no good labor and cooperation to return to the normal social order. He recognized socialism and hoped that the future was equal and the society of great harmony thought that the salvation of the folk art was the salvation of the society, that is, "the folk art saved the world". "Take this as the country to create the world...... If the world is a beautiful country, life is full of beauty... Beauty must be the majority, and if there is only a few beauty, beauty is limited. If only a few people work, the world is no longer beautiful... The most extensive communication with people's life is the craft. The decline of the craft will not usher in a beautiful country... The craft here is not the arts and crafts of a few people. The folk art is produced by most people. It is for most people's work. It is used by most people and is indispensable in daily life. The folk art is to make the world become a necessary condition for beauty of the country, such as religious salvation vows, for salvation and the need for a religious era"

Good social form, is the beauty of the process is the survival of the soil. Soetsu Yanagi is keen to see that the capital society produces the surplus value and the profit is the ultimate goal. The frenzy of consumerism brought about by the accompanying consumerism has eroded the virtues of reference and treasure. Only from the impetuous return to calm, to achieve the cultural legacy of 
genuine asylum. Soetsu Yanagi sees art as a way to the nation of beauty. The folk art is to save the world and reinvent the nation by means of the folk art.

\section{The Craft of the People, the Design of the Society}

Artists rely on talent to create works, and the craftsmen produce ordinary things through heavy labor. Soetsu Yanagi seems more art is approaching ideal is, and the process is closer to the reality will be beautiful. Art is great and noble. We must look up from a distance. Once we get close to it, there will be no dignity. People usually hang high on the wall, but utensils can be touched nearby. The first Soetsu Yanagi folk art for the corresponding English "folk art", but eventually made the word "Folk-craft English".

"Folk-craft" and "art-craft" show two different judgments about art for technology. John, Raskin and William Morris want to transform the society by upgrading technology to artistic status. Art (Art) and the process appears to be different in Liu Shi and more not to be art and light technology, he believes that technology is life appliance of the people, is a great and noble and superior beauty in stark contrast to the close and warm beauty, so he will be classified as folk art and craft art. Folk art, public art, is a collective creation or capital machinery manufacturing, has the quantity, low cost characteristics; namely the art technology, art, personal, or noble personality technology process skills for making less expensive. One is for everyday life, one is to satisfy the taste of personality.

In Liu's view of folk art than art also contains the beauty of the process, namely the use of the same personality, personal art; beauty is a kind of beauty can not be denied, but the folk art represents the highest level of the United States, which is beyond the realm of my personal beauty. Among the masses, the people's carefree beauty and natural care are the source of beauty. Soetsu Yanagi here is a service consciousness, morality, sociality, naturalness and religiosity in the folk art, emphasizing the beauty of national tradition and the beauty of social harmony.

Today, about ninety years of the birth of the folk art theory and the civil art cause, the Japanese design has shown its outstanding form to the world. Earl, a design critic, summarized the Japanese design from the form and style characteristics: one is colorful, decorative, gorgeous and creative; the other is monochromatic, straight line, modified, simple and simple. Today, Japan is designed to carry forward the traditional design spirit of national tradition with the traditional and modern dual rules, and also highlights the distinctive features of modernity. One way is the traditional national aesthetics, traditional, warm and historical, constantly succinct traditional Japanese traditional culture on the basis of design and development, has reached a very simple and highly refined. From a theoretical perspective, this situation is the continuation of the aesthetic standard of folk art, and the other way is modern, developing and international way, which is the modern life style of Japanese people. Double contrast, Japanese technology and Japanese design talent, many Japanese design masterpieces, enhance the reputation.

\section{Conclusions}

Today, we have gone far through the simple material age of Soetsu Yanagi, and the boundary of design has gradually melted into the non - material age. The boundary will have design, art, quite distinct from each other in science and technology, economy and culture of fuzzy boundaries, design may organize independent theory system in the system, but the design practice has been unable to separate array. Today's design products in use, concept, imagination, science and technology, foresight, interesting, perceptual and other aspects of the exploration. However, regardless of the changing times, Liu's theory of "use and beauty" is of great significance in contemporary design, and is an eternal topic. As the material level "and beauty", and as aesthetic level of "use and beauty" is now in the field of design evolved into "designs the function and form of relationship", "design and mass" and "design and social morality" and "designer social responsibility" and etc.. Although Soetsu Yanagi's folk art came into existence in the last century, it has lasted for about ninety years. Now, it seems that some theories of Liu Chung Yue are still unable to break through the time and have the particularity of the times. As we can see, Soetsu Yanagi 
constantly perfected the theory of folk art in revision and self-correction, together with the times, he presented the past, present and future of folk art again and again. The beauty which is derived from the spirit of the people is a kind of infinite pursuit and belief.

\section{Acknowledgements}

An initiating man: Peng Fangyan

Project Name: Sichuan Provincial Education Department humanities and Social Sciences key research base, Sichuan agriculture characteristic brand development and communication research center project "Sichuan agricultural product ecological packaging design research".

Item number: CAB1405

\section{References}

[1] Toshimitsu I. Beauty of Folkcraft-An Buddhist Aesthetics by Soetsu Yanagi [J]. Aesthetics, 1976, 27(3):23-34.

[2] Fu-Ye Y U. The Significance of Soetsu Yanagi's Folk Art Thought on Chinese Traditional Handicraft Protection [J]. Journal of Jilin College of the Arts, 2013.

[3] Take K. Introduction to theThelogy of Excellent Beauty (No.5): People's Arts and Religion from theViewpoint of Yanagi Soetsu[J]. Doshisha Womens College of Liberal Arts Annual Reports of Studies, 1984, 35:275-289.

[4] Tsutsui M. 'Object' and 'Emotion' in Yanagi Soetsu [J]. Hikone Ronso, 1996, 302:37-60.

[5] Take K. Introductionto the Theology of Excellent Beauty (No. 4): People's Arts and Religion onthe View Point of Soetsu Yanagi [J]. Doshisha Womens College of Liberal Arts Annual Reports of Studies, 1983, 34:340-355.

[6] Take K. Introduction to the Theology of Excellent Beauty (No. 1): Soetsu Yanagi and Doshisha [J]. Doshisha Womens College of Liberal Arts Annual Reports of Studies, 1980, 31:334-356.

[7] Bailey P. Korea's Choson Dynasty Ceramics: Beyond Yanagi Soetsu's 'Beauty of Sorrow' Discourse [J]. Japanese Studies, 2013.

[8] Yanagi S. Folk Arts of Ryukyu [J]. Japanese Journal of Ethnology, 1950, 15:166-171.

[9] Rousmaniere N. Yanagi in America: Soetsu Yanagi’s Two Extended Stays in the United States and Their Impact on America [J]. Nber Chapters, 1996, 76(76):343-355.

[10] Take K. Introduction tothe theology of Excellent Beaty (No. 3): People's Arts and Religion on theview point of Soetsu Yanagi[J]. Doshisha Womens College of Liberal Arts Annual Reports of Studies, 1982, 33:303-321. 